\title{
Extinction risks from climate change: macroecological and historical insights \\ Roland Jansson
}

Address: Department of Ecology and Environmental Science, Umeå University, SE-901 87 Umeå, Sweden

Email: roland.jansson@emg.umu.se

Fl000 Biology Reports 2009, 1:44 (doi:10.3410/BI-44)

The electronic version of this article is the complete one and can be found at: http://FI000.com/Reports/Biology/content///44

\begin{abstract}
Human-induced climate change may threaten a large proportion of Earth's biota, but the uncertainties involved in projecting the future geographical distributions of species make quantitative predictions of extinction risk difficult to make. I discuss how insight from recent advances in macroecology and knowledge about species responses to past climate change can help predict extinction risks more accurately.
\end{abstract}

\section{Introduction and context}

Current rates of species extinction have been inferred to be orders of magnitude above background levels, based on well known groups with a fossil record $[1,2]$, but whether these taxa are representative for biodiversity in general is not known. There is concern that we are currently entering a mass extinction event comparable to the previous five greatest mass extinctions in the history of life [3]. Currently, most human-induced extinctions result from habitat destruction and overexploitation of species [4]. Climate change caused by greenhouse gas emissions may become a similarly severe threat [5], and will add to present challenges for global biodiversity. The ability to assess the potential species loss is hampered by insufficient knowledge about biodiversity. The number of species on Earth is not known even to the order of magnitude [6], and the geographic distributions and ecology is poorly known for most taxa described by science.

Extinctions of species where climate change is thought to be the ultimate cause may have already occurred [7], but pinpointing the ultimate cause of an extinction event is difficult. To assess the magnitude of the problem in the future, modelling is required. Despite the challenge of incomplete knowledge, rough predictions of the number of species threatened with extinction by climate change have been made [8-10]. The general method in such predictions has been to project the degree of habitat loss expected as a result of geographic range adjustments in response to climate change, and then use species-area equations to assess potential species loss as a result of range contractions. Depending on the climate change scenario used and dispersal ability of species, Thomas et al. [9] projected that $18-35 \%$ of species are at risk of extinction in their sample of regions across the Earth. The paper and similar efforts are controversial, however, and both the methods [11] and the way the results have been presented in the media [12] have been criticized. Nevertheless, realistic predictions of climate-driven extinction risk are needed for climate mitigation and species conservation efforts.

The accuracy of extinction risk predictions depends on the ability to project how species will adjust to climate change. To survive climate change that is beyond its tolerance, a species may either adapt to the new climate locally, or shift its geographical distribution to climatically suitable areas. A critical question is whether species will be able to evolve tolerance to new climatic conditions at the pace of climate change. Species distribution models utilize species distribution records and correlations with climate to project where species will occur in the future under the assumption of no 
evolutionary change [13]. These models are not only used to predict extinction risk, but by providing projections of where species may occur in a future climate, they form the basis of adaptation strategies to conserve biodiversity [14]. When the ability of species distribution models to predict future distributions has been checked, however, their performance has been less than satisfying [15], although the methods are rapidly improving [16]. Reasons for poor model performance and inconsistencies among models include variation among climate change scenarios, poor species distribution data, variation in modelling methods, and violation of model assumptions. One way of gaining insight into the constraints and opportunities offered by extinction risk assessments is to examine how species have responded to similar climatic challenges in the past, and to examine how biodiversity is distributed at large spatial scales and the underlying causes of this distribution, sometimes referred to as 'macroecology'.

\section{Major recent advances}

Below I highlight recent advances in the knowledge of how species adjust their ranges in response to climate change now and in the past, which may help assess the risk for climate-induced species extinctions.

\section{Adaptations and evolutionary responses to climate change} If species can evolve rapidly enough in response to climate change, projections of extinction risk based on species distribution modelling may be overestimated. Recent empirical evidence suggests that evolution is responsive to climate variation and may occur at rates that make evolutionary change a plausible alternative to geographical range shifts [17]. Adaptive evolution in local populations may, however, be counteracted by competition from immigrating organisms pre-adapted to the new climate [18]. The dominant response to Quaternary climate changes comprised geographical range shifts rather than morphological adaptation in situ [19]. Evolutionary change and geographic range shifts are, however, not mutually exclusive alternatives. Both in situ persistence and range shifts may involve evolutionary processes that enhance adaptations to new climatic conditions - for example, by selection for enhanced tolerance in migrating populations [20].

\section{Observed responses to present climate change}

An increasing body of data documents that species and assemblages respond to warming as predicted by models, adjusting their ranges polewards and towards higher elevations. This lends support to bioclimatic modelling approaches and projections of species extinction. The most common data record latitudinally expanding range limits of temperate taxa colonizing habitats that have become climatically suitable [21-23]. Records of latitudinal range contractions are mostly anecdotal [24], but a few recent studies document elevational range shifts [25-27]. Range shifts on tropical mountains in response to warming raise double concerns [28]; many high-elevational species are at risk of becoming extinct if mountains are 'too low' to offer them habitat after the climate zones have shifted upwards. In addition, tropical lowlands might be depleted of species as more and more species shift their ranges towards higher latitudes and elevations [28]. Data on range shifts from tropical mountains have been mostly missing, but recently Chen et al. [25] documented 102 insect species shifting their distributions an average of $62 \mathrm{~m}$ upwards on Mount Kinabalu, Borneo, between 1965 and 2007. Raxworthy et al. [27] found that 30 species of reptiles and amphibians had shifted their elevational midpoints upslope by 19-51 m on Madagascar, in agreement with recent regional warming.

The role of climate and dispersal in limiting species ranges Some climate types are predicted to completely disappear, threatening species assemblages living in these vanishing environments with extirpation [29]. In the majority of cases, however, the environments of species will shift geographically to various degrees, necessitating modelling of range adjustments and extinction risk. Species distribution modelling rests on the assumption that ranges are bounded by climate. Beale et al. [30] found that null models of species-climate associations established using bioclimatic models were no better than chance for 68 of 100 European bird species. Many factors other than climate, such as species interactions and human impact, set the limit of species ranges, all contributing to weaken species-climate associations. If species do not occur everywhere their climatic requirements are met (global dispersal) due to migration barriers, this will also reduce the ability of projecting future geographic distributions. As a result, modelled climatic tolerances will be more narrow than real ones, overstating extinction risk. On the other hand, such a situation also implies that many species are likely to have problems colonizing new areas that become climatically suitable. Svenning and Skov [31] found that European tree species occupy only $38 \%$ of their calculated potential climatic ranges. Frequent successful naturalizations of tree species outside their native ranges confirm the climatic suitability of modelled potential ranges. If dispersal limitation is common, species or species diversity patterns cannot be expected to be in steadystate with contemporary climate. The pattern of diversity for European tree species with restricted ranges was best explained by climatic conditions occurring at the last glacial maximum about 21,000 years ago, whereas the 
diversity of widely distributed species correlates with present day climate [31]. This suggests that some species were unable to expand their ranges following deglaciation and Holocene warming to occupy their potential niches. This interpretation is supported by the demonstration that species richness of tree species in northern Europe can be explained by differential rates of dispersal out of glacial refugia [32]. In line with these results, Araújo et al. [33] demonstrated that species richness of narrow-ranging amphibians and reptiles in Europe was better explained by climatic stability between the last glacial maximum and the present day than by the present climate.

A question related to dispersal limitation in explaining present distributions is whether species will be able to keep up with future climate change. Models of species' future distributions usually assume either full adjustment of species ranges - that is, that species can colonize any suitable habitat - or no range adjustment at all, implying only range contraction in response to climate change [9]. The truth should be somewhere in between. The finding that species richness of butterflies in Britain increases with climate change, but that species richness change lags behind climate change [34] sheds some light on this question. Generalist species responded quicker than specialist ones, suggesting that species with high specialization and low vagility will have the greatest difficulties in tracking their habitat. Lag times should be longer and dispersal barriers more difficult to overcome in taxa less vagile than butterflies.

When using information on how species responded to past climatic shifts, we are faced with a conundrum. Climate shifts during the Quaternary were thought to be as rapid and large as those expected during the 21st century [35]. Despite that, extant species survived many such events, and documented extinctions were few [36]. Does this imply that the problem of climate-induced extinctions has been overstated? Closer examination of the data demonstrates that this is probably not the case. First, assemblages that have been 'filtered' by a previous challenge or catastrophe usually experience little extinction when faced by similar subsequent challenges [37]. For example, the first continental glaciation in Europe in the Plio-Pleistocene caused a wave of extinction in, for example, tree species [38], but the following glacial periods resulted in few extinctions, despite an increase in the amplitude of climate shifts. The first cooling event pruned the European tree species pool of cold-intolerant taxa, whereas the remaining taxa could persist. Secondly, present global climate is close to the peak average temperature attained during the Quaternary [35]. Future warming will result in a climate warmer than recorded for millions of years [35]. Many species have never experienced such a situation, potentially resulting in extinction of intolerant taxa. Thirdly, during previous climatic shifts, species were able to shift their distributions without interference from humans. Humans now dominate most ecosystems, resulting in barriers to dispersal and combined threats of climate change, habitat destruction and overexploitation of species. The combined effect of human overexploitation and climate change has been implicated in the extinction of the megafauna in Eurasia and America at the beginning of the Holocene. Bioclimatic models show that the ranges of many species, such as the woolly mammoth, drastically declined during deglaciation [39], but megafaunal species had survived many similar climate shifts in the past, and the coup de grâce was probably caused by human hunting [40].

\section{Geographic patterns in species vulnerability}

Where are species most at risk from climate change? Given that observed and projected climate change is larger towards the poles, most attention has been directed towards high-latitude environments [41], with polar bears as iconic species in the public mind. Depending on the vulnerability of species, geographic patterns of extinction risk may, however, deviate from geographic patterns of warming. Deutsch et al. [42] showed that tropical insects are more sensitive to warming than high-latitude ones, because they already live close to their limit of climatic tolerance, whereas the fitness of many high-latitude species may increase as a result of warming. Moreover, tropical assemblages contain more species with poor dispersal ability, high specialization and small geographic ranges [43], all characteristics that make them vulnerable to climate change. McCain [44] recently found support for Janzen's hypothesis [45] that the elevational range sizes of organisms are smaller on tropical than high-latitude mountains, making them more vulnerable to warming and upslope range shifts. Narrow range-sizes also mean that for many tropical mountain species there will be no overlap between present and projected future distributions, increasing the risk for dispersal failure and extinction [28]. In an assessment of global extinction risk in birds, Jetz et al. [46] projected many extinctions of tropical narrow-ranged species, although land conversion is presently a greater threat than climate change. As a result of narrow climatic tolerances, relatively small temperature changes may have large effects on species distributions in the tropics. In a record of forest turnover during 48,000 years in the Amazon basin, forest cover was found to be continuous, but a temperature change of only $1{ }^{\circ} \mathrm{C}$ during the transition from glacial to Holocene resulted in a large turnover in species composition [47]. 


\section{Future directions}

Even if the assumptions in bioclimatic models are frequently violated, they remain a primary strategy to project the future of biodiversity. The methods are also developing rapidly, with prospects of accounting for variability among models and relaxing some of the critical assumptions $[13,48]$. Information on how species responded to climate change in the past serves as a 'reality check' of model projections. Further advances could be made by taking advantage of new knowledge about past climate change. For example, studies of species responses to Pleistocene climate oscillations have focused on the role of refugia, with recent interest in microrefugia (survival of taxa in small habitat pockets), to explain the speed of post-glacial recolonization [49]. The concept of microrefugia should also be relevant in projecting the effects of climate change [50]. Survival in small patches may be incorporated into models, and management and creation of microrefugia could be used as an active adaptation strategy.

An area in need of more research is the relationship between species tolerances and climate change. Some species may be more tolerant than indicated by present species-environment relationships, whereas others live close to their tolerance limits. Better information about the vulnerability of taxa in different regions is also desirable. Much of our present knowledge is derived from studies of Europe and North America, which may not be relevant for the rest of the world, such as the hotspots of species richness and endemism where most of Earth's biodiversity reside. Rapid progress in this field is urgently needed to avoid the prospect of a wave of climate change-induced extinction becoming inevitable.

\section{Competing interests}

The author declares that he has no competing interests.

\section{Acknowledgements}

The author thanks Robert Colwell and Oswald Schmitz, who greatly improved the manuscript with their comments. The author acknowledges support from The Swedish Research Council, The Swedish Research Council Formas and a Young Researcher Award from Umeå University.

\section{References}

I. Pimm S, Raven P, Peterson A, Sekercioglu CH, Ehrlich PR: Human impacts on the rates of recent, present, and future bird extinctions. Proc Natl Acad Sci U S A 2006, 103:1094|-6.

FI000 Factor 3.0 Recommended Evaluated by Guy Midgley 18 Jul 2006

2. Regan HM, Lupia R, Drinnan AN, Burgman MA: The currency and tempo of extinction. Am Nat 2001, 157:1-10.
3. Wake DB, Vredenburg VT: Are we in the midst of the sixth mass extinction? A view from the world of amphibians. Proc Natl Acad Sci U S A 2008, 105: I 1 466-73.

4. Bibby CJ: Recent past and future extinctions in birds. Philos Trans $R$ Soc Lond Ser B Biol Sci 1994, 344:35-40.

5. Sala OE, Chapin FS, Armesto Jl, Berlow E, Bloomfield J, Dirzo R, Huber-Sanwald E, Huenneke LF, Jackson RB, Kinzig A, Leemans R, Lodge DM, Mooney HA, Oesterheld M, Poff NL, Sykes MT, Walker BH, Walker M, Wall DH: Global biodiversity scenarios for the year 2100. Science 2000, 287:1770-4.

6. May RM: How many species are there on earth? Science 1988, 24|:|44|-9.

7. Pounds JA, Bustamante MR, Coloma LA, Consuegra JA, Fogden MPL, Foster PN, La Marca E, Masters KL, Merino-Viteri A, Puschendorf R, Ron SR, Sánchez-Azofeifa GA, Still CJ, Young BE: Widespread amphibian extinctions from epidemic disease driven by global warming. Nature 2006, 439:161-7.

FI000 Factor 8.4 Exceptional

Evaluated by Yvonne Graeser 18 Jan 2006, Gabriele Sorci 18 Jan 2006, Edmund Brodie 20 Jan 2006, Mark Lonsdale 10 Feb 2006

8. Midgley GF, Hannah L, Millar D, Rutherford MC, Powrie LW: Assessing the vulnerability of species richness to anthropogenic climate change in a biodiversity hotspot. Glob Ecol Biogeogr 2002, I I:445-5I.

9. Thomas CD, Cameron A, Green RE, Bakkenes M, Beaumont LJ, Collingham YC, Erasmus BFN, de Siqueira MF, Grainger A, Hannah L, Hughes L, Huntley B, van Jaarsveld AS, Midgley GF, Miles L, OrtegaHuerta MA, Peterson AT, Phillips OL, Williams SE: Extinction risk from climate change. Nature 2004, 427:145-8.

10. Sekercioglu $\mathrm{CH}$, Schneider SH, Fay JP, Loarie SR: Climate change, elevational range shifts, and bird extinctions. Conserv Biol 2008, 22: $140-50$.

II. Thuiller W, Araújo MB, Pearson RG, Whittaker RJ, Brotons L, Lavorel S: Biodiversity conservation: uncertainty in predictions of extinction risk. Nature 2004, 430:I p following 33; discussion following 33.

12. Ladle RJ, Jepson P, Araújo $M B$, Whittaker RJ: Dangers of crying wolf over risk of extinctions. Nature 2004, 428:799.

13. Elith J, Graham $\mathrm{CH}$, Anderson RP, Dudik M, Ferrier S, Guisan A, Hijmans RJ, Huettmann F, Leathwick JR, Lehmann A, Li J, Lohmann LG, Loiselle BA, Manion G, Moritz C, Nakamura M, Nakazawa Y, Overton JM, Peterson AT, Phillips SJ, Richardson K, Scachetti-Pereira R, Schapire RE, Soberon J, Williams S, Wisz MS, Zimmermann NE: Novel methods improve prediction of species' distributions from occurrence data. Ecography 2006, 29:|29-5|.

14. Hannah L, Midgley GF, Millar D: Climate change-integrated conservation strategies. Glob Ecol Biogeogr 2002, I I:485-95.

15. Araújo MB, Pearson RG, Thuiller W, Erhard M: Validation of species-climate impact models under climate change. Glob Change Biol 2005, II:1504-13.

16. Elith J, Graham CH: Do they? How do they? WHY do they differ? On finding reasons for differing performances of species distribution models. Ecography 2009, 32:66-77.

17. Skelly DK, Joseph LN, Possingham HP, Freidenburg LK, Farrugia TJ, Kinnison MT, Hendry AP: Evolutionary responses to climate change. Conserv Biol 2007, 21:1353-5.

18. de Mazancourt C, Johnson E, Barraclough TG: Biodiversity inhibits species' evolutionary responses to changing environments. Ecol Lett 2008, I I:380-8.

19. Bennett KD: Evolution and Ecology: the Pace of Life. Cambridge: Cambridge University Press; 1997.

20. Davis MB, Shaw RG, Etterson JR: Evolutionary responses to changing climate. Ecology 2005, 86: I704-I4.

21. Parmesan C, Ryrholm N, Stefanescu C, Hill JK, Thomas CD, Descimon H, Huntley B, Kaila L, Kullberg J, Tammaru T, Tennent WJ, Thomas JA, Warren M: Poleward shifts in 
geographical ranges of butterfly species associated with regional warming. Nature 1999, 399:579-83.

22. Parmesan C, Yohe G: A globally coherent fingerprint of climate change impacts across natural systems. Nature 2003, 42 I:37-42.

23. Root TL, Price JT, Hall KR, Schneider SH, Rosenzweig C, Pounds JA: Fingerprints of global warming on wild animals and plants. Nature 2003, 421:57-60.

24. Thomas CD, Franco AMA, Hill JK: Range retractions and extinction in the face of climate warming. Trends Ecol Evol 2006, 21:4I 5-6.

25. Chen IC, Shiu HJ, Benedick S, Holloway JD, Cheye VK, Barlow HS, Hill JK, Thomas CD: Elevation increases in moth assemblages over $\mathbf{4 2}$ years on a tropical mountain. Proc Natl Acad Sci U S A 2009, 106: |479-83.

FI000 Factor 6.0 Must Read

Evaluated by Robert Colwell 06 Mar 2009

26. Lenoir J, Gegout JC, Marquet PA, de Ruffray P, Brisse H: A significant upward shift in plant species optimum elevation during the 20th century. Science 2008, 320:|768-7|.

FI000 Factor 4.8 Must Read

Evaluated by Robert Sterner 02 Jul 2008, Valerie Eviner II Jul 2008

27. Raxworthy C], Pearson RG, Rabibisoa N, Rakotondrazafy AM, Ramanamanjato JB, Raselimanana AP, Wu S, Nussbaum RA, Stone DA: Extinction vulnerability of tropical montane endemism from warming and upslope displacement: a preliminary appraisal for the highest massif in Madagascar. Glob Change Biol 2008, I4:1703-20.

28. Colwell RK, Brehm G, Cardelus CL, Gilman AC, Longino JT: Global warming, elevational range shifts, and lowland biotic attrition in the wet tropics. Science 2008, 322:258-6I.

29. Williams JW, Jackson ST, Kutzbach JE: Projected distributions of novel and disappearing climates by 2100 AD. Proc Natl Acad Sci U S A 2007, 104:5738-42.

FI000 Factor 3.0 Recommended

Evaluated by Virginia Dale 0I Jun 2007

30. Beale CM, Lennon JJ, Gimona A: Opening the climate envelope reveals no macroscale associations with climate in European birds. Proc Natl Acad Sci U S A 2008, 105:14908-12.

FI000 Factor 3.0 Recommended

Evaluated by Guy Midgley 15 Jan 2009

31. Svenning JC, Skov F: Limited filling of the potential range in European tree species. Ecol Lett 2004, 7:565-73.

FI000 Factor 3.0 Recommended

Evaluated by Helene Muller-Landau 15 Mar 2005

32. Svenning JC, Skov F: Could the tree diversity pattern in Europe be generated by postglacial dispersal limitation? Ecol Lett 2007 , 1 0:453-60.

FI000 Factor 6.0 Must Read

Evaluated by George Hurtt 27 Nov 2007

33. Araújo MB, Nogués-Bravo D, Diniz-Filho JAF, Haywood AM, Valdes PJ, Rahbek C: Quaternary climate changes explain diversity among reptiles and amphibians. Ecography 2008, 3 I:8- 15.

FI000 Factor 3.0 Recommended

Evaluated by Roland Jansson 25 Feb 2008

34. Menendez R, Megias AG, Hill JK, Braschler B, Willis SG, Collingham Y, Fox $R$, Roy DB, Thomas $C D$ : Species richness changes lag behind climate change. Proc R Soc B Biol Sci 2006, 273:|465-70.

FI000 Factor 6.0 Must Read

Evaluated by Albert van Jaarsveld 23 Aug 2006
35. Overpeck J, Cole J, Barlein P: A “paleoperspective” on climate variability and change. In Climate Change and Biodiversity. Edited by Overpeck J, Cole J, Barlein P: New Haven: Yale University Press; 2005, 91-108.

36. Botkin DB, Saxe H, Araujo MB, Betts R, Bradshaw RHW, Cedhagen $T$, Chesson P, Dawson TP, Etterson JR, Faith DP, Ferrier S, Guisan A, Hansen AS, Hilbert DW, Loehle C, Margules C, New M, Sobel MJ, Stockwell DRB: Forecasting the effects of global warming on biodiversity. Bioscience 2007, 57:227-36.

FI000 Factor 3.0 Recommended

Evaluated by David Lindenmayer 3 Jan 2008

37. Balmford A: Extinction filters and current resilience: the significance of past selection pressures for conservation biology. Trends Ecol Evol 1996, I I:193-6.

38. Svenning JC, Skov F: Ice age legacies in the geographical distribution of tree species richness in Europe. Glob Ecol Biogeogr 2007, 16:234-45.

FI000 Factor 6.0 Must Read

Evaluated by Roland Jansson 5 Apr 2007

39. Nogués-Bravo D, Rodiguez J, Hortal J, Batra P, Araújo MB: Climate change, humans, and the extinction of the woolly mammoth. PLOS Biol 2008, 6:685-92.

FI000 Factor 3.0 Recommended

Evaluated by Barry Brook 05 Feb 2009

40. Alroy J: A multispecies overkill simulation of the endPleistocene megafaunal mass extinction. Science 200I, 292: 1893-6.

4I. Intergovernmental Panel on Climate Change: Climate change 2007: Synthesis Report. Contribution of Working Groups i, ii and iii to the Fourth Assessment. Edited by Pachauri RK, Reisinger A: [core writing team]: Geneva Intergovernmental Panel on Climate Change 2007.

42. Deutsch CA, Tewksbury J, Huey RB, Sheldon KS, Ghalambor CK, Haak DC, Martin PR: Impacts of climate warming on terrestrial ectotherms across latitude. Proc Natl Acad Sci U S A 2008, 1 05:6668-72

FI000 Factor 4.8 Must Read

Evaluated by Ary Hoffmann 02 Jun 2008, Roland Jansson 02 Sep 2008

43. Dynesius M, Jansson R: Evolutionary consequences of changes in species' geographical distributions driven by Milankovitch climate oscillations. Proc Natl Acad Sci U S A 2000, 97:9| I5-20.

44. McCain CM: Vertebrate range sizes indicate the mountains may be 'higher' in the tropics. Ecol Lett 2009, I 2:550-60.

FI000 Factor 3.0 Recommended

Evaluated by Michael Angilletta 22 May 2009

45. Janzen DH: Why mountain passes are higher in the tropics. Am Nat 1967, 101:233-49.

46. Jetz W, Wilcove DS, Dobson AP: Projected impacts of climate and land-use change on the global diversity of birds. PLoS Biol 2007, 5:|2||-9.

47. Bush MB, Silman MR, Urrego $\mathrm{DH}: 48,000$ years of climate and forest change in a biodiversity hot spot. Science 2004, 303:827-9.

FI000 Factor 9.0 Exceptional

Evaluated by Robert Colwell I5 Apr 2008

48. Araújo $M B$, New $M$ : Ensemble forecasting of species distributions. Trends Ecol Evol 2007, 22:42-7.

49. Rull V: Microrefugia. J Biogeogr 2009, 36:48I-4.

50. Petit RJ, Hu FS, Dick CW: Forests of the past: a window to future changes. Science 2008, 320:|450-2. 